\title{
Imagem, história e ciência
}

Ana Maria Mauad

Universidade Federal Fluminense

Marcos Felipe de Brum Lopes

Museu Casa de Benjamin Constant, IBRAM/MinC

\begin{abstract}
When working to make documentaries of ethnological, zoological, botanical or geographical interest, faithful documentation is, of course, my first consideration and the pictorial point of view has very often to be discarded (BALDI, Mario. A cameraman in Central Brazil. Photo Magazin, Munique, out. 1954. Coleção Mario Baldi, MB-P-PC-C3/136. Secretaria Municipal de Cultura de Teresópolis, Rio de Janeiro).
\end{abstract}

Pensar sobre a relação entre história, imagem e ciência levanta, inevitavelmente, questões de intertextualidade e reflexões sobre protocolos de representação da realidade. A ideia de que as imagens permanecem no imaginário social como ícones das culturas das quais fazem parte pode ser útil para compreendermos que elas, como qualquer produção humana, são suportes de relações sociais, estão envolvidas em jogos de poder, arenas discursivas e conflitos de toda sorte. É possível fazer ciência com imagens, produzir imagens da ciência e mapear imagens que conformam a noção de tempo e de história.

As imagens despertam julgamentos estéticos e críticas filosóficas, sempre articulados com as culturas dos que as produzem e de seus leitores, seja no processo histórico que caracterizou o tempo de sua criação e circulação, seja no tempo em que elas se tornam fontes e documentos para os estudos dos autores aqui reunidos. Os meios pelos quais elas circulam redefinem seus usos, funções e significados.

As imagens são ricas e, por vezes, podem parecer comunicar mais do que se quer mostrar. Como percebemos na confissão feita certa vez pelo fotógrafo Mario Baldi, que lemos na epígrafe dessa introdução, não é difícil encontrar no vocabulário sobre imagens a ideia de que é preciso adestrá-las, apará-las ou despi-las de supostos excessos, principalmente quando se quer uma imagem objetiva e útil ao conhecimento científico. É como se elas tivessem uma vida própria que deveríamos compreender para, por que não, escová-las a contrapelo. Como sugere W. J. T. Mitchell (2005), imagens podem ter vidas, amores e demandar coisas de nós, que as criamos.

Essa vida das imagens não se dá, porém, fora das dimensões dos processos históricos, e são algumas das múltiplas formas e alguns dos diversos campos de possibilidades desses processos que estão reunidos nesses estudos. Em diferentes sociedades e períodos históricos, ver e conhecer foram princípios de elaboração do conhecimento sobre o mundo. Mediado pelo sentido da visão, o produto dessa relação pôde gerar, por sua vez, imagens em suportes variados. Elas passam, então, a mediar o conhecimento por meio de seus usos e funções, bem como da circulação a que são submetidas. Na produção historiográfica, a compreensão de que os regimes de visualidade definem os limites do 'ver' estabelece os campos de possibilidades da produção da História enquanto ciência humana. Assim, os regimes

MAUAD, Ana Maria; LOPES, Marcos Felipe de Brum. Imagem, História e Ciência. Boletim do Museu Paraense Emílio Goeldi. Ciências Humanas, Belém, v. 9, n. 2, p. 283-286, maio-ago. 2014. DOI: http://dx.doi.org/10.1590/1981-81222014000200002.

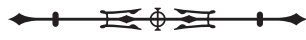


visuais são capazes de agenciar os sentidos da História, ou seja, não haveria uma história por detrás das imagens, mas uma história das imagens e com imagens.

Tudo o que se refere ao visual ou é por ele produzido ganhou, por longo tempo, o estatuto de prova. De Tucídides a Euclides da Cunha, o relato eficiente de um evento seria aquele produzido por uma testemunha ocular. Portanto, uma imagem, por se ancorar em grande medida no campo do visual, ocupa lugar destacado no discurso científico de maneira ampla. As imagens podem ser, ao mesmo tempo, resultados de visões da realidade material, bem como meios de visualização de dimensões invisíveis a olho nu. Seja como for, o uso das imagens como evidências e provas é sempre contingente e histórico. Caberia, portanto, indagar como e com qual objetivo são utilizadas pelo discurso científico e historiográfico, sendo que neste último os debates recentes já apontam para a superação da epistemologia da prova rumo a uma história das representações (Knauss, 2006).

Diante desses problemas, os textos reunidos neste Dossiê debatem a natureza do conhecimento produzido por meio de imagens técnicas, compreendendo que a produção desse tipo de imagem esteve associada às práticas de representar tecnicamente o mundo sobre o qual se queria agir, em geral, associadas às perspectivas cientificistasobjetivistas, que colocavam limites às operações de imagens associadas à imaginação e à magia. As abordagens agora reunidas debruçam-se sobre os diferentes tipos de registro visual da experiência humana, os quais assumem uma dimensão técnica, um saber-fazer diferenciado pelas condições materiais e intelectuais de cada sociedade.

Reunimos um conjunto de análises nas quais se buscam levantar questões teórico-metodológicas que envolvem produção de conhecimento com imagens nos campos das ciências humanas. Os autores apresentam as condições para se mapearem as possibilidades e os limites da articulação entre imagem, história e ciência. $\bigcirc$ quadro de questões se organiza por meio da avaliação do papel da imagem etnográfica na produção de discursos científicos e de como eles definem as narrativas da humanidade em sua diversidade étnica e cultural; da imagem técnica como mediadora de conhecimento e suas implicações em posturas de objetividade (fotografia) e subjetividade (memória); da análise de algumas séries de imagens que desempenharam papel importante na definição do campo científico desde o século XVIII, através da classificação, ordenação e diferenciação da realidade feitas por meio de imagens.

Os nove artigos que compõem o Dossiê compreendem abordagens que envolvem um conjunto variado de temas e problemáticas, entre as quais: as viagens científicas; as questões raciais em gravuras e pinturas de viagem; a fotografia e a medicina; a fotografia e as reformas urbanas; o cinema e os discursos visuais. São acrescidos de uma seção voltada para a memória da prática de pesquisa com imagens no campo da Antropologia, organizada em torno da experiência que o antropólogo e fotógrafo Milton Guran vivenciou na costa ocidental da África.

Iniciamos o Dossiê pelo artigo de Christian Feest, no qual elege obras de artistas do sul da Alemanha, datadas do início do século XVI, que gravitavam em torno da representação da 'gente de Calicute', espaço imaginado e prenhe de sentidos. Essas obras, por sua vez, são articuladas pelo pesquisador a outras imagens de diferentes procedências que figuram no sul da Ásia, além de artefatos do Brasil, por meio de protocolos e metodologias desenvolvidos nesse período para coletar, processar e sistematizar dados de pesquisa através de textos, imagens e coleções de objetos, práticas em que se podem identificar os princípios das modernas estratégias da etnografia e da antropologia.

Na sequência, Mauricio Lissovsky nos orienta pelos caminhos do debate sobre a atualidade dos escritos de Aby Warburg (1866-1929). Destaca-se, em sua análise, como alguns dos mais importantes pensadores da estética na atualidade propõem uma genealogia para suas reflexões que encontra, nos escritos de Warburg, uma espécie de matriz originária. Lissovsky propõe recompor a trajetória de pensadores que assumem para si o legado de Warburg - incluindo

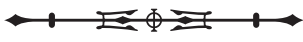


seus sucessores na direção do Instituto Warburg, entre eles Ernst Gombrich e Erwin Panofsky - para sistematizar os principais conceitos e procedimentos warburguianos que encontram eco na atualidade. Entretanto, a importante contribuição deste artigo reside na sugestão de que, por meio das reflexões de Walter Benjamin sobre a potência da imagem, os pensadores atuais estão se apropriando e lendo Warburg. Isso nos provoca a pensar sobre os intertextos que compõem o pensamento atual sobre a visualidade.

A abordagem de Ronald Raminelli e Bruno Silva tem como objeto de estudo as estampas que representam os tapuias, produzidas pelo naturalista português Alexandre Rodrigues Ferreira durante a sua conhecida Viagem Filosófica (1783-1792). Adota-se o ponto de vista das teorias setecentistas, as quais propunham taxonomias que hierarquizavam os grupos humanos de acordo com seu progresso técnico. Para tanto, sistematizam-se os estudos sobre os principais pensadores do século XVIII, em busca de se estabelecer como os escritos desses teóricos foram fundamentais para a produção das imagens na Viagem Filosófica. Observa-se, na análise proposta pelos autores, a estreita relação entre o pensamento iluminista e o uso de imagens como forma de amplificar o texto escrito, ampliando visualmente a descrição proposta verbalmente.

Para compor a discussão sobre as representações na medicina, o artigo de James Roberto Silva analisa o papel da fotografia na produção do conhecimento médico ocidental. Seu recorte temporal engloba as séries fotográficas produzidas entre a segunda metade do século $X I X$ e a primeira do século $X X$, momento em que a fotografia se consolidou como registro objetivo do mundo visível, um instrumento a serviço da divulgação das práticas médicas, que tinha nas publicações especializadas seu principal veículo. $\bigcirc$ foco da análise recai sobre o papel das fotografias na elaboração do universo de representação das práticas médicas e sobre as implicações do uso heurístico da fotografia na medicina.

O estudo de Maria Inez Turazzi reflete sobre a trajetória de Antonio Lopes Mendes (1835-1894), agrônomo português, que participou de viagens para diferentes partes do mundo, integrando missões científicas e comerciais. A pesquisadora se debruça sobre o rico material resultante da trajetória do agrônomo, muito do qual ainda inédito, para avaliar sua sensibilidade na expressão visual da experiência vivenciada em suas viagens, o que resultou em material iconográfico de grande valor. Aborda a produção visual do agrônomo em suas viagens pelo Brasil entre 1882 e 1883, para compreender a natureza interdisciplinar e as formas de comunicação do conhecimento científico pelas artes visuais no século XIX.

A relação entre imagem, técnica e representação da guerra é o cerne da reflexão apresentada no artigo de Rogério Rosa Rodrigues, que tem como objetivo analisar a relação que o Exército brasileiro manteve com a tecnologia fotográfica ao final do século XIX e início do século XX. Sua análise apoia-se em dois importantes acervos, produzidos nas campanhas de Canudos e do Contestado, por meio dos quais avalia o investimento da corporação nos usos e nas funções da fotografia. Nesse caso, a técnica fotográfica foi utilizada como forma de registro comprobatório, e serviu para se combaterem as críticas à ação do Exército na repressão de ambos os conflitos. Avaliam-se, portanto, os usos e as funções da imagem fotográfica em situação de guerra, associada ao registro de acontecimentos por parte de fotógrafos engajados na causa militar, bem como as representações fotográficas dos dois conflitos, marcando-se as diferenças em relação às formas como a morte e a destruição nos campos de batalha foram registradas.

Rebeca Monroy Nasr nos convida a refletir sobre o impacto na imprensa mexicana da representação fotográfica das 'auto-viúvas', orientando-nos pelos percursos da construção narrativa dos acontecimentos feita pela imprensa ilustrada do México nos anos 1920. Trata-se do caso da Miss México de 1928, que se converteu em 'auto-viúva' no ano seguinte, acontecimento que é trabalhado pela autora como índice da vida pós-revolucionária mexicana, destacandose sua análise sobre questões de gênero e de classe que perpassavam os conflitos cotidianos em um momento de modernização provocado pelas políticas governamentais. $\bigcirc$ estudo elege as imagens fotográficas como documentos

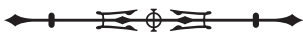


privilegiados para a avaliação das transformações no cotidiano social, inserindo a análise nos jogos de escala de uma história cultural, que investe no episódico e no local para o conhecimento de uma cultura ampla.

A produção de um olhar etnológico para a interpretação de filmes e para delinear o debate sobre o campo cinematográfico brasileiro entre 1970-1980 é o desafio que a abordagem de Francisco das Chagas Fernandes Santiago Júnior nos propõe. Em suas considerações, o autor relaciona crítica cinematográica a discurso etnográfico para configurar um lugar de fala sobre as representações da cultura popular no cinema. Em sua abordagem, considera a dinâmica dos agentes e suas posições, tanto no campo cinematográfico quanto no campo das ciências sociais e da cultura, o que lhe garante uma reflexão crítica e bem fundamentada do ponto de vista da análise histórica dos discursos e de seus efeitos no mundo social.

A reflexão proposta por Cláudia Sanz investe na avaliação de como a categoria do instante adquire um lugar relevante no cenário epistemológico moderno. Sua análise reúne um conjunto de experiências em torno da fotografia instantânea, principalmente aquela relacionada à cronofotografia, colocado em perspectiva com o pensamento filosófico sobre o tempo, que se elaborava na segunda metade do século XIX. Trata-se de uma análise complexa, a qual busca compreender o tempo fotográfico como dimensão do ato de conhecer e como princípio cognitivo, mas também busca avaliar como a fotografia participou da formulação de campos de saber variados.

Como um desfecho possível do conjunto de reflexões, propõe-se um olhar sobre a experiência do antropólogo e fotógrafo Milton Guran, estruturada sobre o uso da fotografia na pesquisa social. O relato apresenta dois tempos da pesquisa antropológica realizada nas Repúblicas do Benin e do Togo, em 1996 e 2010, sobre a construção da identidade agudá. Em seu relato, Guran enfatiza o papel da fotografia como plataforma privilegiada de observação e de registro de fenômenos sociais visualmente relevantes, que apoia a produção de conhecimento cientificamente controlado sobre as sociedades fotografadas. Acompanham a reflexão três pares de imagens fotográficas produzidas nos dois tempos da pesquisa de campo (1996-2010), para evidenciar os processos de atualização das tradições e dos marcadores identitários da comunidade agudá.

Como organizadores do Dossiê, desejamos excelentes leituras e esperamos responder às perguntas propostas, mas, sobretudo, instigar novos questionamentos. Portanto, ainda que correndo o risco de sermos seduzidos pelas imagens, nos propomos a enfrentá-las.

\section{REFERÊNCIAS}

KNAUSS, Paulo. O desafio de fazer História com imagens: arte e cultura visual. ArtCultura, Uberlândia, v. 8, n. 12, p. 97-115, jan.-jun. 2006.

MITCHELL, W. J. T. What do pictures want? The lives and loves of images. Chicago: The University of Chicago Press, 2005.

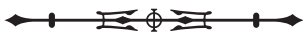

